\section{IUPAC Elections for the 2022-2023 Term} very two years, IUPAC holds an election for its officers and committee members. About 120 individuals are to be elected or reelected either as Titular Members, Associate Members, or National Representatives. Information concerning the voting process and the role of each kind of member is contained in the Union bylaws (see https://iupac.org/ who-we-are/organizational-guidelines/).

Any qualified individual who is interested in being nominated is invited to contact his/her National Adhering Organization (NAO) and/or the current committee officers. The election will cover a two-year term that will start in 2022. Every division committees and standing committees will have vacancies. As part of the nomination procedure, NAOs are invited to submit curriculum vitae for each nominee to the IUPAC Secretariat no later than 1 February 2021.

In addition, Affiliate members in good standing who are current for the years 2020 and 2021 are eligible to participate in the nomination process via self-nomination. They are eligible for AM positions on Divisions and Standing Committees, irrespective of country of residence. Similarly, employees of current Company Associates are eligible for AM positions.

Elections for each committee will take place during the second trimester of 2021 and the 2022-2023 memberships for all committees will be finalized during the next IUPAC General Assembly in August 2021.

Individuals interested in becoming IUPAC officers or members of the IUPAC Bureau should contact their NAOs. Nominations for officers have a different timeline can only be made by an NAO. Officers elections will take place at the Council Meeting during the next General Assembly in Montreal.

\section{Expected duties and qualifications}

Each member of an IUPAC body (Division, Standing Committee, or Commission) is expected to become an active participant in the work of the body in helping to decide on the program and in reviewing proposals for projects. These duties require the members to have expertise in the relevant disciplinary area and also to be able to exercise sound scientific judgment. Much of each Committee's work is conducted by e-mail correspondence.

In a concerted effort to improve membership diversity, nominations for well-qualified female chemists, "younger" chemists with the required expertise, and industrial chemists are encouraged. Each nomination for consideration for membership on a Division or Standing Committee or Commission must identify the intended Committee or Commission and must be accompanied by a curriculum vitae. Each nominee will be considered for all vacant positions on the Committee unless otherwise specified. Nominations will only be accepted through the online form, to be available 15 October 2020.

Contact information for all NAOS and division and standing committee officers is available on the IUPAC website, or upon request at the IUPAC Secretariat; e-mail <secretariat@iupac.org>.

\section{IUPAC Announces the 2020 Top Ten Emerging Technologies In Chemistry}

UPAC has released the results of its 2020 search for the Top Ten Emerging Technologies in Chemistry. The goal of this project is to showcase the value of Chemistry and to inform the general public as to how the chemical sciences contribute to the well-being of society and the sustainability of Planet Earth. Following the same guidance as it did last year, the jury identified emerging technology as one in between a new scientific discovery and a fully-commercialized technology, and one that has the capacity to open new opportunities in chemistry and beyond. The 2020 finalists are (in alphabetical order):

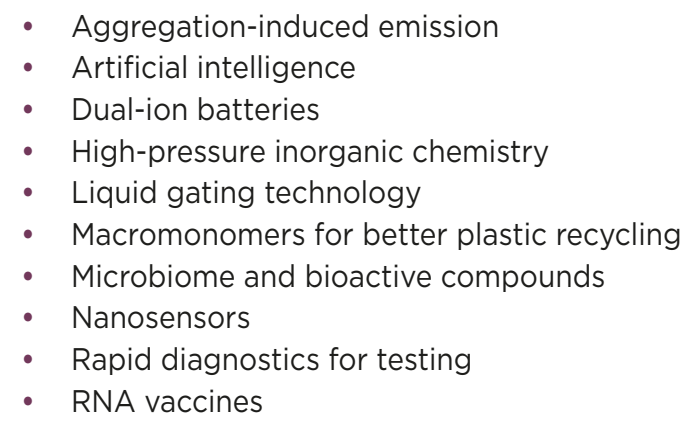

"The selected technologies will change our world for the better, making a more thoughtful use of our resources, favoring more efficient transformations, and providing more sustainable solutions in applications ranging from new materials and more efficient batteries to extremely precise sensors and personalized medicine" wrote Fernando Gomollón-Bel in a feature published is this issue Chemistry International (see page 3) outlining details of each of these technologies. The jury* was an international group of objective and unbiased experts 